\title{
Anaesthesia for open wrist fracture surgery in adults/elderly
}

\section{[version 1; peer review: 2 approved]}

\section{Irene Sellbrandt ${ }^{1}$, Metha Brattwall ${ }^{1}$, Margareta Warrén Stomberg², Pether Jildenstål3 , Jan G. Jakobsson (iD) 4}

\footnotetext{
${ }^{1}$ Anaesthesiology and Intensive Care, Sahlgrenska University Hospital, Mölndal, Sweden

${ }^{2}$ The Sahlgrenska Academy Institute of Health and Care Sciences, University of Gothenburg, Gothenburg, Sweden

${ }^{3}$ Department of Anaesthesiology and Intensive Care Medicine, The Sahlgrenska Academy Institute of Health and Care Sciences, Gothenburg University, Gothenburg, Sweden

${ }^{4}$ Department of Anaesthesia \& Intensive Care, Institution for Clinical Science, Karolinska Institute, Danderyd University Hospital, Stockholm, Sweden
}

\section{V1 First published: 13 Nov 2017, 6:1996 \\ https://doi.org/10.12688/f1000research.13004.1 \\ Latest published: 13 Nov 2017, 6:1996 \\ https://doi.org/10.12688/f1000research.13004.1}

\section{Abstract}

Anaesthetic technique for open surgery of acute distal for arm fracture in adults/elderly is not well defined. Regional anaesthesia, general anaesthesia or a combined general and regional block may be considered. General anaesthetic technique, the timing and drug/drug combination for the regional block must also be considered. This is a study around published studies assessing anaesthtic technique for wrist surgery. A systematic database search was performed and papers describing the effect of anaesthetic techniques were included. We found sparse evidence for what anaesthetic technique is optimal for open wrist fracture repair. In total only six studies were found using our inclusion criteria, which all supported the short term, early recovery benefits of regional anaesthesia as part of multi-modal analgesia. More protracted outcomes and putting the type of block into context of quality of recovery and patients' satisfaction is lacking in the literature. The risk for a pain rebound when the block vanishes should also be acknowledged. Therefore, further high quality studies are warranted concerning the anaesthetic technique for this type of surgery.

\section{Keywords}

open wrist surgery, anaesthetic technique, regional anaesthesia, general anaesthesia, postoperative pain

\section{Open Peer Review}

Approval Status

1 2

version 1

13 Nov 2017
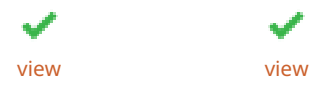

1. Jan Hendrik Eshuis, University of

Amsterdam, Amsterdam, The Netherlands

2. Colin F. Royse ID, University of Melbourne,

Melbourne, Australia

Any reports and responses or comments on the article can be found at the end of the article. 
Corresponding author: Jan G. Jakobsson (jan.jakobsson@ki.se)

Author roles: Sellbrandt I: Data Curation, Formal Analysis, Methodology, Writing - Original Draft Preparation; Brattwall M: Conceptualization, Methodology, Writing - Original Draft Preparation; Warrén Stomberg M: Conceptualization, Data Curation, Methodology, Resources, Writing - Original Draft Preparation, Writing - Review \& Editing; Jildenstål P: Conceptualization, Writing Original Draft Preparation; Jakobsson JG: Conceptualization, Data Curation, Methodology, Writing - Original Draft Preparation, Writing Review \& Editing

Competing interests: No competing interests were disclosed.

Grant information: The author(s) declared that no grants were involved in supporting this work.

Copyright: @ 2017 Sellbrandt I et al. This is an open access article distributed under the terms of the Creative Commons Attribution License, which permits unrestricted use, distribution, and reproduction in any medium, provided the original work is properly cited.

How to cite this article: Sellbrandt I, Brattwall M, Warrén Stomberg $M$ et al. Anaesthesia for open wrist fracture surgery in adults/elderly [version 1; peer review: 2 approved] F1000Research 2017, 6:1996 https://doi.org/10.12688/f1000research.13004.1

First published: 13 Nov 2017, 6:1996 https://doi.org/10.12688/f1000research.13004.1 


\section{Introduction}

Fracture on the upper limb is common, and fracture on the distal forearm, wrist fracture, is one of most common upper limb fractures. Whether the incident increases or declines at least among women is a matter of discussion ${ }^{1,2}$. The incidence is increasing among adults and elderly in Sweden ${ }^{3}$. There are certainly several factors contributing to the increased risk; the fact that individuals are becoming more active at later stages of life and osteoporosis is prevalent in older individuals are both likely to have importance. In addition, there is seasonal variation of distal wrist fracture with high risk during winter months $s^{4,5}$.

The best treatment of wrist fracture is debated. Data from the Swedish fracture register ${ }^{1,6}$ shows that approximately $20 \%$ of acute wrist fractures undergo open surgery. In 2009, Smektala et $a .^{7}$ conducted a cohort study around surgical wrist fracture care in Germany. They found that most patients were elderly females, and the predominant fracture management procedure was percutaneous K-wire osteosynthesis (56\% of cases), followed by plate osteosynthesis (44\%) and more than half of patients had general anaesthesia $(55 \%)$.

Surgical repair of wrist fracture can be performed under various anaesthetic techniques. Studies assessing anaesthetic technique, whether regional anaesthesia, general anaesthesia or a combined general and regional anaesthetic approach provides the best perioperative care are not well defined. Currently, there is no firm evidence to support a best technique and no clear consensus guidance is available.

The aim of this study was to identify the currently available data regarding anaesthetic technique, general, regional or combined general and regional anaesthesia, and postoperative pain course for open surgical repair of wrist fracture in adults and elderly.

\section{Methods}

\section{Search strategy}

A systematic database search was performed on PubMed, Scopus and Cochrane databases, searching for articles in the period from 2007 to October 2017 (the last 10 year period), to identify studies regarding the impact of anaesthesia method on pain and long term outcomes after open radius fracture repair. Quantitative as well as qualitative English language studies limited to adults were searched.

The search strategy used the following text words or Medical Subject Headings (MeSH): "Radius fractures, Wrist injuries, Surgery, Anaesthesia, Regional anaesthesia, Pain, Postoperative, Clinical outcome", combined search for the last 10 years; (radius fractures OR wrist injuries OR wrist fractures) AND anesthesia. The result was further analysed by two of the

${ }^{1}$ https://stratum.registercentrum.se/\#!page?id=1094 authors and secondary papers searched from the initial studies retrieved.

\section{Inclusion and exclusion criteria}

Observational studies and case series were excluded, as it was considered that these could be associated with major bias. Study selection was based on an initial screen of titles and abstracts, and then reading the final identified articles. Papers with at least two different techniques assessing clinical peroperative effects were included.

Selection of papers and subsequent extraction was performed independently by two of the authors (MWS and JGJ). Consensus was reached for final article inclusion and data extraction through discussion between all authors.

\section{Data extraction}

A standard data extraction matrix was conducted manually, to gather study information including: references/year of publication/ author, anaesthesia method, postoperative pain before and after discharge from hospital.

\section{Results}

Figure 1 describes the search results from the literature.

In total, 6 studies, 4 prospective randomised and 2 retrospective studies of various designs, were identified, which altogether included 619 participants (prospective, $n=238$; retrospective, $\mathrm{n}=381$ ) (see Table 1).

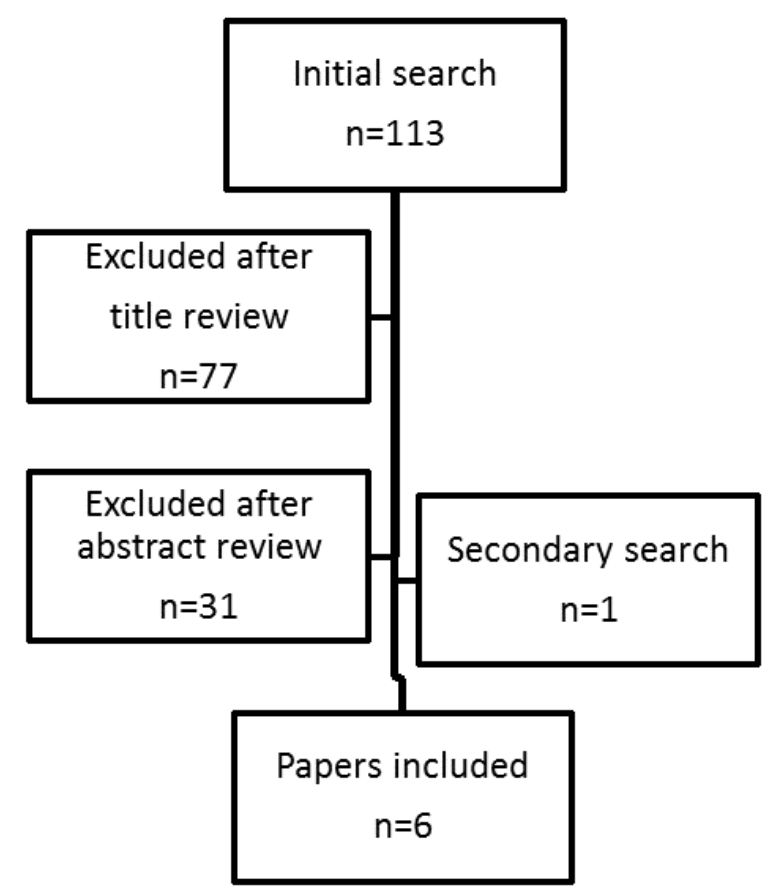

Figure 1. Flowchart showing the literature search results. 
Table 1. Studies included concerning anaesthesia technique for open wrist fracture surgery in adults/elderly. GA, general anaesthesia; RA, regional anaesthesia; IRA, intravenous regional anaesthesia (Bier block).

\begin{tabular}{|c|c|c|c|c|c|}
\hline References & Design & $\begin{array}{l}\text { Number of } \\
\text { patients }\end{array}$ & Anaesthesia method & $\begin{array}{l}\text { Postop pain before } \\
\text { discharge }\end{array}$ & $\begin{array}{l}\text { Postop pain after } \\
\text { discharge }\end{array}$ \\
\hline $\begin{array}{l}\text { Hadzic et al, } \\
\text { Anesthesiology } 2004\end{array}$ & $\begin{array}{l}\text { Prospective } \\
\text { randomised }\end{array}$ & $\begin{array}{l}50 \text { patients } \\
\text { Aged 18-65 } \\
\text { years }\end{array}$ & $\begin{array}{l}\text { RA: Infraclavicular plexus } \\
\text { block + propofol sedation } \\
\text { (chloroprocaine) } \\
\text { GA: propofol/desflurane + } \\
\text { local infiltration }\end{array}$ & $\begin{array}{l}\text { Assessed until } \\
\text { discharge } \\
\text { RA less pain and } \\
\text { no need for rescue, } \\
\text { earlier discharge }\end{array}$ & $\begin{array}{l}\text { No difference in pain or } \\
\text { pain medication at } 24 \text { and } \\
48 \text { hours, the block group } \\
\text { of patients had less pain } \\
\text { and pain medication } \\
\text { at } 72 \text { hours }\end{array}$ \\
\hline $\begin{array}{l}\text { Egol et al, J } \\
\text { Orthop Trauma } 2012\end{array}$ & Retrospective & 187 patients & $\begin{array}{l}\text { RA ( } n=65) \text { : Infra clavicular } \\
\text { plexus block (LA not } \\
\text { presented) } \\
\begin{array}{l}\text { GA ( } n=122) \text { : not further } \\
\text { presented }\end{array}\end{array}$ & Not assessed & $\begin{array}{l}3,6 \text { and } 12 \text { month follow } \\
\text { up showed better pain and } \\
\text { functional course for RA } \\
\text { group }\end{array}$ \\
\hline $\begin{array}{l}\text { Sunderland et al, } \\
\text { Reg Anesth Pain } \\
\text { Med } 2016\end{array}$ & Retrospective & 195 patients & $\begin{array}{l}\text { RA }(n=118) \text { : Supra or infra } \\
\text { clavicular block (LA not } \\
\text { presented) } \\
\text { GA }(n=77) \text { : not further } \\
\text { presented }\end{array}$ & $\begin{array}{l}\text { GA more early pain } \\
\text { before discharge and } \\
\text { unplanned health care } \\
\text { resource utilization } \\
\text { due to pain }\end{array}$ & $\begin{array}{l}\text { RA more self-reported } \\
\text { severe pain and - higher } \\
\text { unplanned visits up to } \\
48 \text { hours }\end{array}$ \\
\hline $\begin{array}{l}\text { Galos et al, } \\
\text { Clin Orthop Relat Res } \\
2016\end{array}$ & $\begin{array}{l}\text { Prospective } \\
\text { randomised }\end{array}$ & 36 patients & $\begin{array}{l}\text { RA ( } n=18) \text { : Infraclavicular } \\
\text { plexus block (combined } \\
\text { lidocaine } 20 \text { mg/ml with } \\
\text { adrenaline and bupivacaine } \\
2.5 \mathrm{mg} / \mathrm{ml}) \\
\text { GA }(n=18) \text { : not further } \\
\text { presented }\end{array}$ & $\begin{array}{l}\text { GA more early pain } \\
\text { before discharge }\end{array}$ & $\begin{array}{l}\text { IRA increase in pain 6-24h } \\
\text { postop, no difference } \\
48,72 \text { and at } 2 \text { weeks }\end{array}$ \\
\hline $\begin{array}{l}\text { O'Neil et al, } \\
\text { Am J Orthop } 2017\end{array}$ & $\begin{array}{l}\text { Prospective } \\
\text { randomised }\end{array}$ & 98 patients & $\begin{array}{l}\text { RA ( } n=53) \text { : Single } \\
\text { shot supraclavicular } \\
\text { block (ropivacaine + } \\
\text { dexamethasone) } \\
\text { GA }(n=45) \text { : not further } \\
\text { presented }\end{array}$ & Not specified & $\begin{array}{l}\text { Opioid consumption was } \\
\text { equivalent for general and } \\
\text { regional anaesthesia up } \\
\text { to } 2 \text { weeks after surgery. } \\
\text { Mean duration of opioid } \\
\text { use was } 4.8 \text { days with a } \\
\text { significant trend toward } \\
\text { less consumption with } \\
\text { increasing age }\end{array}$ \\
\hline $\begin{array}{l}\text { Holmberg et al, } \\
\text { Anaesthesia } 2017\end{array}$ & $\begin{array}{l}\text { Prospective } \\
\text { randomised }\end{array}$ & 52 patients & $\begin{array}{l}\text { All patents received GA } \\
\text { (TIVA) } \\
\text { RA pre- or post-op } \mathrm{n}=26 \\
\text { each: Infraclavicular plexus } \\
\text { block (ropivacaine } 7.5 \mathrm{mg} / \mathrm{ml} \text { ) }\end{array}$ & $\begin{array}{l}\text { Postoperative pain } \\
\text { scores were higher } \\
\text { and more patients } \\
\text { required rescue } \\
\text { analgesia during the } \\
\text { first } 4 \mathrm{~h} \text { after surgery } \\
\text { in the postoperative } \\
\text { block group }\end{array}$ & $\begin{array}{l}\text { Preoperative block showed } \\
\text { a better pain course. } \\
\text { The risk for rebound was } \\
\text { commented }\end{array}$ \\
\hline
\end{tabular}

Overall, it could be seen that there is little information around anaesthetic techniques used, and base pain medications is sparsely addressed. The focus has been on early and intermediate pain and opioid consumption. Pain was assessed with different scales in each study.

\section{Prospective randomised studies}

Hadzic et al. ${ }^{8}$ performed a study in 2004 comparing general anaesthesia to infraclavicular plexus block with short-acting local anaesthesia for hand and wrist surgery. They included 52 patients; however 2 were excluded from analysis, resulting in 50 patients; 25 each in general and regional anaesthesia were evaluated. The focus was on early recovery during the stay in hospital, but patients were also called on the telephone once daily for days 1, 2 and 3 and interviewed about pain felt. In addition, 2 weeks later the patients were asked about satisfaction and willingness to have the same anaesthesia. They found that the block group needed approximately 5 minutes longer time for preparation prior to surgery, but more patients in the block group were eligible for early recovery room bypass. The block group also experienced less pain, nausea, sore throat and fatigue. The block group were eligible for discharge at a significantly faster rate that the anaesthesia group. Pain at follow-up did not differ at day 1 and 3 between the two groups, but was found in favour, lower pain, for 
block group of patient at day 3. Satisfaction with anaesthesia at 2 weeks was found to be the same, but willingness to have same anaesthesia favoured the block technique.

Galos et $\boldsymbol{a l} .{ }^{9}$ randomized patients to general anaesthesia $(\mathrm{n}=18)$ or plexus block $(n=18)$ and followed postoperative pain $2,4,6$, $12,24,48$ and 72 hours after surgery. They found that the general anaesthesia group had more pain 2 hours postoperatively, but regional anaesthesia experienced more pain 12 and 24 hours after surgery, termed "rebound pain", as compared to the general anaesthesia patients. There were no differences in pain ratings at 48 and 72 hours or at 2 weeks. Follow-up of function at 2 and 6 weeks did not show any differences.

O' Neil et al ${ }^{10}$ studied 98 patients, 45 receiving general anaesthesia and 53 regional anaesthesia, a single shot peripheral block, for preoperative management. They had a questionnaire follow-up at a 2-week follow-up visit where the amount of pain medication used was requested. They did not find any difference in opioid need between general and regional anaesthesia groups. Opioid need decreased, however, with age and increased in relation to the severity of the fracture.

Holmberg $\boldsymbol{e t} \boldsymbol{a l}{ }^{11}$ studied 52 patients with fractured radius. The study compared pre- and post-operative block, in both groups combined with general anaesthesia total intravenous anaesthesia (TIVA). The patients were randomized to a preoperative $(n=25)$ or a postoperative $(n=26)$ infraclavicular plexus block. Time to the first rescue analgesic, as well as pain score evaluation, was at 1 , 2, 4, 8 and 24 hours after surgery. Patients were further called for phone interview on day 7 and 6 months postoperatively, and asked about pain, rescue analgesia daily function and side effects. The time for needing first rescue opioid analgesic was significantly longer for the pre-operative block group (544 vs 343 minutes). There was also a significantly lower mean VAS pain score at 30 minutes, 1, 2 and 4 hours. Pain was, however, not different after 4 hours and beyond. At day 7 more patients in the postoperative block group needed oral paracetamol as compared to the preoperative group; however, the total opioid need was the same. During the first postoperative night, most patients from both groups experienced severe pain. Follow-up at 6 months showed no difference in pain; median pain score in the pre-operative group was 2 as compared to the postoperative group median of 1 .

\section{Retrospective studies}

Egol et $\boldsymbol{a l} .{ }^{12}$ published a retrospective register study in 2012 assessing pain after wrist surgery. Included in the analysis were 122 patients that had surgery under general anaesthesia and 65 under a regional block. Patients were followed up for analysis at 3, 6 and 12 months after surgery; pain and function was assessed. At 3 and 6 months, patient that had regional anaesthesia showed significantly less pain and better function; however, at 12 months groups were equal in pain assessment, and function measured by the test were similar and normalised, back to normal range.

Sunderland et $\boldsymbol{a l} .{ }^{13}$ conducted a retrospective review, for a retrospective quality improvement project, to assess the need for unplanned medical visits caused by pain in the first 48 hours after wrist surgery and the impact of anaesthetic technique, general anaesthesia or regional block. All 77 patients who had general and 118 patients who had regional anaesthesia were reached for follow-up interview within 6 weeks, which posed the question "In the first 24 to 48 hours after surgery, did you need to seek medical attention for pain?". The block group was found to have significantly more unplanned visits ( $20 \%$ vs $5 \%$ ), and selfreported severe pain was also more common in this group of patients (41\% vs 10\%), as compared to the general anaesthesia group of patients. Patients were also asked about persistent postoperative pain and if they had been diagnosed with a "complex regional pain syndrome" (CRPS). No difference in development of chronic pain or diagnosis of CRPS was found between the two groups.

\section{Discussion}

Most wrist fractures in adults and the elderly can be managed by close reposition. However, certain fractures require open reposition and fixation at initial examination, and others fail close reposition and fixation therapy and thus require an open procedure. Wrist surgery is not uncommonly performed as day or overnight stay surgery and is common in elderly patients. Thus, it is of importance to consider various outcomes when comparing anaesthetic techniques used in these procedures and on these patients.

We found only six papers explicitly addressing anaesthetic technique for open acute distal arm surgery. The pharmacological effect of blocking nociceptive influx is clear; preoperative block seems better than post-surgery block. The effect beyond the early period and duration of the pharmacological blockade was more diverse between studies, and it seems that the risk for "rebound" pain should be acknowledged.

The benefits of prevention of pain and the concept of multi modal analgesia have been known for decades ${ }^{14}$. The importance of multi-modal analgesia is well-accepted, and today this standard of care is especially important in ambulatory surgery ${ }^{15}$. The application of local anaesthetics in the wound area, site for incision, or as a peripheral block, is a basic part of the multi-modal analgesia concept. The effects of peripheral block on early pain, reducing the need for opioid analgesics are well-known ${ }^{16}$. The effects beyond the early period and the duration of the pharmacological local block is less well documented ${ }^{17}$. There are several options to improve the duration by the addition of adjuncts e.g. alf-2blocking agents, such as clonidine or dexmedetomidine; however, the prolongation of the block resolution by liposomal bupivacaine preparation needs further studies ${ }^{18}$.

Hadzic et al. used propofol followed by desflurane and Holberg et al. describes general anaesthesia as TIVA for all patients, the general anaesthetic techniques used were not further addressed. Awakening/emergence from anaesthesia is faster when inhaled anaesthesia has been used, shown by many previous studies ${ }^{19,20}$. The benefits of the use of nitrous oxide to quicken emergence is also well documented ${ }^{21,22}$. The impact of low blood gas solubility on awakening is also shown with xenon as the main 
anaesthetic ${ }^{23}$. Xenon does promote stable intraoperative haemodynamic and rapid recovery, as compared to traditional halogenated inhaled anaesthetics ${ }^{24}$. The classic study by Apfel et al. verified the importance of multi-modal PostOperative Nausea and Vomiting - PONV prophylaxis ${ }^{25}$. Appropriate risk based PONV prophylaxis should be administered reducing its occurrence ${ }^{26}$. The benefits of propofol-based anaesthesia to reduce early PONV is well known ${ }^{27}$.

From the six studies identified, the blocks were done with different techniques and solutions. The studies by Hadzic et al., Egol et al., Galos et al. and Holmberg et al. used sole infraclavicular block technique, while Sunderland et al. used mixed infraand supraclavicular block technique and O'Neil et al. used sole supraclavicular blocks. The local anaesthetics used differed as well: Hadzic et al., chloroprocaine; Galos et al., mixed lidocaine and bupivacaine; O'Neil et al., ropivacaine and dexamethasone; Holmberg, ropivacaine. Adding adjuncts to increase the analgesic block duration is of interest, but generally is off-label use, and there is no firm consensus about what drug and concentration should be used ${ }^{\text {xiii }}$. There is a recent review suggesting dexmedetomidine is superior to clonidine as adjunct for supraclavicular block, but there is also a risk of side effects ${ }^{28}$.

We did not address anaesthesia/analgesia/sedation for closed reduction; there is a Cochrane review around anaesthesia for the close reposition from $2002^{29}$. Pain associated with the performance of local anaesthetic blockade was not evaluated in this study but may be further taken into consideration in the patient's participation in anaesthetic decision.

It is obvious that further high quality studies are warranted; studies assessing not only early but more protracted outcome variables. For example, effect on logistics, theatre time, patients eligible for fast-track, bypassing recovery area and time to discharge should all be included. Effects beyond discharge need to also be assessed in a standardised fashion, pain and analgesic requirement at least up to a week post-surgery and quality of recovery should be assessed by a standardised tool. There are today at least two well-accepted tools for the assessment of quality of recovery, the PostopQRS and the Quality of Recovery scale ${ }^{30}$. The long-term outcome and the risk for chronic pain is dependent on several factors and the impact on anaesthetic technique may not have major impact. Long term outcomes are of importance, but the impact on training, rehabilitation surgical technique and even osteoporosis must be acknowledged when assessing long-term results. Similarly, considerations must be taken that wrist fracture may initiate complex regional pain syndrome type I. For instance, severe fractures and women are at high risk for development this syndrome after surgical treatment of distal radius fractures (Roh et al., 2014) ${ }^{31}$.

In conclusion, there is sparse evidence for what anaesthetic technique is superior for open wrist repair. The short term, early recovery benefits of regional anaesthesia as part of multimodal analgesia is well documented; however, more protracted outcomes and putting the type of block into context of quality of recovery and patients' satisfaction is lacking. The risk for pain rebound when the block finishes should also be acknowledged. Further high quality studies are warranted.

\section{Competing interests}

No competing interests were disclosed.

\section{Grant information}

The author(s) declared that no grants were involved in supporting this work.
1. Abrahamsen B, Jørgensen NR, Schwarz P: Epidemiology of forearm fractures in adults in Denmark: national age- and gender-specific incidence rates, ratio of forearm to hip fractures, and extent of surgical fracture repair in inpatients and outpatients. Osteoporos Int. 2015; 26(1): 67-76. and outpatients. Osteoporos Int. 2015;

2. Dimai HP, Svedbom A, Fahrleitner-Pammer A, et al.: Epidemiology of dista forearm fractures in Austria between 1989 and 2010. Osteoporos Int 2014 25(9): 2297-306

PubMed Abstract | Publisher Full Text

3. Jerrhag D, Englund M, Karlsson MK, et al.: Epidemiology and time trends of distal forearm fractures in adults - a study of $\mathbf{1 1 . 2}$ million person-years in Sweden. BMC Musculoskelet Disord. 2017; 18(1): 240. PubMed Abstract | Publisher Full Text | Free Full Text

4. Hoff M, Torvik IA, Schei B: Forearm fractures in Central Norway, 1999-2012: incidence, time trends, and seasonal variation. Arch Osteoporos. 2016; 11: 7 PubMed Abstract | Publisher Full Text

5. Omsland TK, Ahmed LA, Grønskag A, et al.: More forearm fractures among urban than rural women: the NOREPOS study based on the Troms $ø$ study and the HUNT study. J Bone Miner Res. 2011; 26(4): 850-6. PubMed Abstract | Publisher Full Text

6. Horst TA, Jupiter JB: Stabilisation of distal radius fractures: Lessons learned and future directions. Injury. 2016; 47(2): 313-9. PubMed Abstract | Publisher Full Text
7. Smektala R, Endres HG, Dasch B, et al:: [Quality of care after distal radius fracture in Germany. Results of a fracture register of 1,201 elderly patients] Unfallchirurg. 2009; 112(1): 46-54. PubMed Abstract | Publisher Full Text

8. Hadzic A, Arliss J, Kerimoglu B, et al: A comparison of infraclavicular nerve block versus general anesthesia for hand and wrist day-case surgeries. Anesthesiology. 2004; 101(1): 127-32. PubMed Abstract | Publisher Full Text

9. Galos DK, Taormina DP, Crespo A, et al.: Does Brachial Plexus Blockade Result in Improved Pain Scores After Distal Radius Fracture Fixation? A Randomized Trial. Clin Orthop Relat Res. 2016; 474(5): 1247-54. PubMed Abstract | Publisher Full Text | Free Full Text

10. O'Neil JT, Wang ML, Kim N, et al:: Prospective Evaluation of Opioid Consumption After Distal Radius Fracture Repair Surgery. Am J Orthop (Belle Mead NJ). 2017; 46(1): E35-E40. PubMed Abstract

11. Holmberg A, Sauter AR, Klaastad Ø, et al.: Pre-operative brachial plexus block compared with an identical block performed at the end of surgery: a prospective, double-blind, randomised clinical trial. Anaesthesia. 2017; 72(8): 967-977.

PublMed Abstract | Publisher Full Text

12. Egol KA, Soojian MG, Walsh M, et al:: Regional anesthesia improves outcome after distal radius fracture fixation over general anesthesia. J Orthop Trauma. 
2012; 26(9): 545-9.

PubMed Abstract | Publisher Full Text

13. Sunderland S, Yarnold CH, Head SJ, et al: Regional Versus General Anesthesia and the Incidence of Unplanned Health Care Resource Utilization for Postoperative Pain After Wrist Fracture Surgery: Results From a Retrospective Quality Improvement Project. Reg Anesth Pain Med. 2016; 41(1): 22-7. PubMed Abstract | Publisher Full Text

14. Michaloliakou C, Chung F, Sharma S: Preoperative multimodal analgesia facilitates recovery after ambulatory laparoscopic cholecystectomy. Anesth Analg. 1996; 82(1): 44-51

PubMed Abstract | Publisher Full Text

15. Warren-Stomberg M, Brattwall M, Jakobsson JG: Non-opioid analgesics for pain management following ambulatory surgery: a review. Minerva Anestesiol. 2013; 79(9): 1077-87. PubMed Abstract

16. Jakobsson J, Johnson MZ: Perioperative regional anaesthesia and postoperative longer-term outcomes [version 1; referees: 3 approved] F1000Res. 2016; 5: pii: F1000 Faculty Rev-2501. PubMed Abstract | Publisher Full Text | Free Full Text

17. Brattwall $M$, Jildenstål $P$, Warré Stomberg $M$, et al.: Upper extremity nerve block: how can benefit, duration, and safety be improved? An update [version 1 referees: 3 approved]. F1000Res. 2016; 5: pii: F1000 Faculty Rev-907. PubMed Abstract | Publisher Full Text | Free Full Text

18. Hamilton TW, Athanassoglou V, Mellon S, et al:: Liposomal bupivacaine infiltration at the surgical site for the management of postoperative pain. Cochrane Database Syst Rev. 2017; 2: CD011419. PubMed Abstract | Publisher Full Text

19. Dexter $\mathrm{F}$, Tinker $\mathrm{JH}$ : Comparisons between desflurane and isoflurane or propofol on time to following commands and time to discharge. A metaanalysis. Anesthesiology. 1995; 83(1): 77-82. metaanalysis. Anesthesiology. 1995; 83

20. Wachtel RE, Dexter F, Epstein RH, et al:: Meta-analysis of desflurane and propofol average times and variability in times to extubation and following commands. Can J Anaesth. 2011; 58(8): 714-24. PubMed Abstract | Publisher Full Text

21. Jakobsson I, Heidvall M, Davidson S: The sevoflurane-sparing effect of nitrous oxide: a clinical study. Acta Anaesthesiol Scand. 1999; 43(4): 411-4. PubMed Abstract | Publisher Full Text

22. Einarsson S, Bengtsson A, Stenqvist O, et al.: Decreased respiratory depression during emergence from anesthesia with sevoflurane/ $\mathrm{N}_{2} \mathrm{O}$ than with sevoflurane alone. Can J Anaesth. 1999; 46(4): 335-41.

PubMed Abstract | Publisher Full Text

23. Rasmussen LS, Schmehl W, Jakobsson J: Comparison of xenon with propofol for supplementary general anaesthesia for knee replacement: a randomized study. Br J Anaesth. 2006; 97(2): 154-9. PubMed Abstract | Publisher Full Text

24. Law LS, Lo EA, Gan TJ: Xenon Anesthesia: A Systematic Review and MetaAnalysis of Randomized Controlled Trials. Anesth Analg. 2016; 122(3): 678-97. PubMed Abstract | Publisher Full Text

25. Apfel CC, Korttila K, Abdalla M, et al:: A factorial trial of six interventions for the prevention of postoperative nausea and vomiting. N Engl J Med. 2004; 350(24): 2441-51.

PubMed Abstract | Publisher Full Text | Free Full Text

26. Öbrink $E$, Jildenstål $P$, Oddby $E$, et al:: Post-operative nausea and vomiting: update on predicting the probability and ways to minimize its occurrence, with focus on ambulatory surgery. Int $J$ Surg. 2015; 15: 100-6. PubMed Abstract | Publisher Full Text

27. Kumar G, Stendall C, Mistry R, et al.: A comparison of total intravenous anaesthesia using propofol with sevoflurane or desflurane in ambulatory surgery: systematic review and meta-analysis. Anaesthesia. 2014; 69(10): surgery:

PubMed Abstract | Publisher Full Text

28. El-Boghdadly K, Brull R, Sehmbi H, et al:: Perineural Dexmedetomidine Is More Effective Than Clonidine When Added to Local Anesthetic for Supraclavicular Brachial Plexus Block: A Systematic Review and Meta-analysis. Anesth Analg. 2017; 124(6): 2008-2020. 2017; 124(6): 2008-2020.
PubMed Abstract | Publisher Full Text

29. Handoll $\mathrm{HH}$, Madhok R, Dodds $\mathrm{C}$ : Anaesthesia for treating distal radial fracture in adults. Cochrane Database Syst Rev. 2002; (3): CD003320.

PubMed Abstract | Publisher Full Text

30. Bowyer A, Jakobsson J, Ljungqvist $\mathrm{O}$, et al:: A review of the scope and measurement of postoperative quality of recovery. Anaesthesia. 2014; 69(11): 1266-78.

PubMed Abstract | Publisher Full Text

31. Roh $\mathrm{YH}$, Lee $\mathrm{BK}$, Noh $\mathrm{JH}$, et al:: Factors associated with complex regional pain syndrome type I in patients with surgically treated distal radius fracture. Arch Orthop Trauma Surg. 2014; 134(12): 1775-81. PubMed Abstract | Publisher Full Text 


\section{Open Peer Review}

\section{Current Peer Review Status:}

\section{Version 1}

Reviewer Report 16 January 2018

https://doi.org/10.5256/f1000research.14100.r29364

(C) 2018 Royse C. This is an open access peer review report distributed under the terms of the Creative Commons Attribution License, which permits unrestricted use, distribution, and reproduction in any medium, provided the original work is properly cited.

\section{Colin F. Royse}

Department of Surgery, University of Melbourne, Melbourne, Vic, Australia

The authors have conducted a systematic review to identify if regional versus general anaesthesia is superior for post-operative pain for distal wrist fractures. They correctly show that there is an evidence gap in the literature, and cannot provide recommendation from their data. The study is well conducted, but the contributing trials are all small and have sufficient heterogeneity that it is simply not possible to draw any conclusions, other than more trials need to be done.

Is the work clearly and accurately presented and does it cite the current literature? Yes

Is the study design appropriate and is the work technically sound? Yes

Are sufficient details of methods and analysis provided to allow replication by others? Yes

If applicable, is the statistical analysis and its interpretation appropriate? Not applicable

Are all the source data underlying the results available to ensure full reproducibility? No source data required

Are the conclusions drawn adequately supported by the results? Yes

Competing Interests: No competing interests were disclosed.

I confirm that I have read this submission and believe that I have an appropriate level of expertise to confirm that it is of an acceptable scientific standard. 
Reviewer Report 11 December 2017

https://doi.org/10.5256/f1000research.14100.r28244

(C) 2017 Eshuis J. This is an open access peer review report distributed under the terms of the Creative Commons Attribution License, which permits unrestricted use, distribution, and reproduction in any medium, provided the original work is properly cited.

\section{Jan Hendrik Eshuis}

Department of Anesthesiology, Academic Medical Center, University of Amsterdam, Amsterdam, The Netherlands

The article's title suggests focusing on the elderly but the studies mentioned do not refer especially to the elderly. Although the authors are right in saying that wrist fractures are more common in the elderly it is not clear in the studies mentioned; I suggest to remove "elderly" from the title. In the text it is rightly mentioned.

It is interesting that the article shows a relative lack of information in the literature on this specific wrist fracture treatment. I agree with all the conclusions drawn by the authors about desired further studies; important that is noted that rebound pain in the aftercare phase is higher in the regional group than the multimodal group of patients; this provides us an important "mirror" to our daily practice!

Is the work clearly and accurately presented and does it cite the current literature? Yes

Is the study design appropriate and is the work technically sound? Yes

Are sufficient details of methods and analysis provided to allow replication by others? Yes

If applicable, is the statistical analysis and its interpretation appropriate? Not applicable

Are all the source data underlying the results available to ensure full reproducibility? Yes

Are the conclusions drawn adequately supported by the results? Yes

Competing Interests: No competing interests were disclosed.

Reviewer Expertise: Anesthesiologist, expert in regional anesthesia as well as in ambulatory surgery and anesthesia 
I confirm that I have read this submission and believe that I have an appropriate level of expertise to confirm that it is of an acceptable scientific standard.

The benefits of publishing with F1000Research:

- Your article is published within days, with no editorial bias

- You can publish traditional articles, null/negative results, case reports, data notes and more

- The peer review process is transparent and collaborative

- Your article is indexed in PubMed after passing peer review

- Dedicated customer support at every stage

For pre-submission enquiries, contact research@f1000.com 